\title{
Electronic Educational Resources in Foreign Languages Teaching
}

\author{
Albina Bilyalova \\ Kazan Federal University \\ Nabereznye Chelny, Russia \\ abill71@mail.ru
}

\author{
Nailya Sharypova \\ Kazan State Agricultural \\ University \\ Kazan, Russia \\ snailyah@list.ru
}

\author{
Anifa Akhmetshina \\ Naberezhnye Chelny State \\ Pedagogical University \\ Nabereznye Chelny, Russia \\ anifa.k@gmail.com
}

\author{
Albina Islamova \\ Naberezhnye Chelny State \\ Pedagogical University \\ Nabereznye Chelny, Russia \\ albina0369@mail.ru
}

\begin{abstract}
Information technology is used practically in all spheres of human life. The processes of informatization of society have a strong influence on Education. Moreover, the implementation of new technologies, informatization and computerization nowadays are an integral part of Education. The development of information technologies has led to the emergence of a new form of education "e-learning", that is, education using information and communication technologies. The basis of "e-learning" is electronic educational resources (EER). The purpose of the study is to evaluate the importance of electronic educational resources in teaching foreign languages at Universities. To accomplish the goals and objectives of the study the following methods of research were used: the analysis of pedagogical, didactic, psychological, methodical and special literature, approbation of electronic educational resources, pedagogical experiment and statistical methods of processing of results of the study. The paper concludes important information about various types of electronic educational resources, advantages of using EER in teaching a foreign language, the basic principle of the creation and functioning of EER, the criteria for assessing the quality of EER. The experimental work was done on the basis of Elabuga Institute of Kazan Federal University. The study was carried out with first-year university students of Department of Foreign Languages. The success of the experiment presented in this paper is demonstrated by comparing the results of the test group who were taught using electronic educational resources with the reference group who were taught in a common traditional way. The statistical analysis shows that the test group students had better achievements compared to the reference group. The authors conclude that information communicative technologies, including electronic educational resources nowadays have become one of the main indicators of Education development.
\end{abstract}

Keywords - education, ICT, "e-learning”, electronic educational resources, foreign languages teaching.

\section{INTRODUCTION}

In modern society informatization is one of the most important components of human life and society. The development of global informatization process of society leads to the appearing of not only new information environment of people, but also of new information about their way of life and professional activities.

The using of new technologies, informatization and computerization are now an integral part of Education. So, the process of informatization of society has a strong influence on Education as it is one of the most important mechanisms for reforming the education system with the aim of improving the quality, availability and effectiveness of Education. The development of information technology has led to the emergence of a new form of Education "e-learning", i.e. learning using information and communication technologies. It should be noted here that "e-learning" has a unique advantage - the availability at any time and in any place. In addition, "e-learning" is a powerful way to achieve higher quality and technological progress. Moreover "e-learning" increases the motivation of students; it allows to move from passive to active learning; it creates an information culture, especially from the point of view of its ability to use technology, it ensures the quality of education and provides flexibility for students to access educational sites.

Thus, modern information technologies, which supplement the structure of educational technology, open new prospects to improve the quality of the educational process $[2 ; 3 ; 5 ; 6]$.

It is quite obvious that nowadays educational process is impossible without using information technologies, among which the most important instruments are the electronic educational resources (hereinafter EER). They are the basis for e-learning.

This study analyzes the concept of "electronic educational resource", the description of the types and criteria of quality of electronic educational resources, their advantages and disadvantages, and pedagogical appropriateness and effectiveness of the educational activities of the University students in their use.

Currently, a large number of papers on the use of electronic educational resources have been published $[1 ; 4 ; 7$; 
9]. Despite the extensive experience of using electronic and educational resources in the scientific pedagogical and methodical literature, the possibilities of effective professional training of university bachelors on the basis of these resources have not been fully studied in pedagogical and methodical theory and practice, and the potential of using electronic means to develop skills of students' independent work is not fully revealed.

The question of the use of electronic educational resources in education has become the subject of discussion of teachers and psychologists. Scientists note that the use of electronic educational resources in the educational process ensures the achievement of the following pedagogical goals: development of the student's personality, preparing a student for productive independent activity in the information society; the development of constructive, algorithmic and analytical way of thinking, through interaction with the computer; the development of the ability to make optimal decisions in a problematic situation; the development of research skills; the development of information culture, the ability to process information.

In modern scientific literature there are different approaches to the definition of the EER. Some researchers understand EER as the software, and others state that EER is a kind of information and communication technologies (hereinafter ICT).

In the studies of Dudeney G. it is noted that the educational activities carried out with the use of electronic educational resources are based on the implementation of information activities and information interaction between students, teachers and interactive ICT tool [4]. The main object of such activities is to achieve educational and professional goals. They state that the use of EER in independent learning activities allows to implement modern forms and methods of organization of independent work of students, to carry out the process of its planning, regulation and implementation, to activate cognitive activity, to create educational and methodical support and to organize an integral system of independent work of students on the basis of complex application of EER.

In the study of using EER in foreign languages teaching it is fair to say that almost all researchers favor the idea that the creation and use of EER should meet the requirements of ensuring the integrity of the educational process, the unity of the pedagogical goals of personality development, content, forms, methods of training and provide educational, methodological and psychological and pedagogical support for educational activities.

Thus, mostly all researchers mean by electronic educational resources a common educational space, information environment, information culture. In the article electronic educational resources are understood as an interactive program-methodical resource, built on the principles of modularity with the use of hypertext and multimedia technologies. These materials are aimed at providing students with the capability to easily navigate and select the necessary theoretical material, practical tasks and control tasks; also at receiving assistance with the practical exercises; at conducting self-monitoring according to the studied material; and the implementation of the information retrieval activity of the student when referring to external sources.

\section{Methodology}

Methodological basis of research includes the works of scholars such as Burns M., Dudeney G., Sorin J., Szendeffy R. $[3 ; 4 ; 7 ; 8]$ and others.

To solve the problems set in accordance with the purpose of the study, the following methods of research were used: theoretical methods - the analysis of scientific pedagogical and methodical literature on the development and application of electronic educational resources in Education; empirical methods - questionnaire of students, observation, analysis of the students tests; statistical methods - adapted to the objectives of this study.

The study was conducted in 2 stages. The first stage is the study of the problem of the use EER in teaching foreign languages, based on the literature on methodology, psychology, educational theory and practice; also it includes identification of specific EER requirements, which ensure the development of linguistic and communication competence and increase the interest and motivation of students.

The second stage included the analysis and synthesis of experimental work on the use of EER at the lessons of a foreign language, assessment of EER as a means of improving the efficiency of the process of teaching foreign languages. The experimental work was done on the basis of Elabuga Institute of Kazan Federal University.

\section{The Use of EER In Foreign Language Teaching}

Next, we would like to clarify the description of various types of electronic educational resources, the basic principles of the functioning of the EER, the identification of criteria for assessing the quality of EER, and also the description of the advantages and disadvantages of using EER in foreign languages teaching.

\section{A. Types of EER}

In the educational process various types of electronic educational resources can be used. The feasibility and effectiveness of certain types are discussed in the works of scholars and methodologists $[2 ; 3 ; 4]$. The study of their works allows us to introduce the following types:

Educational EER: they provide quality of learning and can form the basis of development of student competence.

Individual EER: they contribute to the implementation of different types of individual work and develop the ability to analyze and select the right study material, the ability of critical thinking skills of students.

Demo EER: they allow to visualize the studied objects, phenomena, processes, and provide a visual representation of any educational information in general. 
Training EER: they are designed to develop all sorts of skills (hard and soft), revision and consolidation of the studied material.

Diagnostic and testing EER: they assess the knowledge, skills of the student, they are used to establish the level of training, the development of personal qualities, the level of intellectual development.

Supervisory EER: they automate the processes of control (self-control) of learning outcomes, determining the level of mastery of educational material.

Expert EER: they manage the learning process, organize the dialogue between the user and the learning system in solving learning tasks.

Communicative EER: they provide the ability to access any information in local and global networks, and provide remote interactive interaction of subjects.

Computing EER: they automate the processing the results of the training experiment, calculations, measurements in the considered processes and phenomena.

Service EER: they ensure the safety and comfort of the user on the computer.

Leisure EER: they include computer games and computer communications for leisure and extracurricular activities for the purpose of education and personal development of the students.

Each of these types of EER has its own functional appointment, e.g.: Educational EER contains a large amount of information and a significant amount of multimedia content that is perfectly suited for work in class and home: explanation of new material, demonstration of multimedia materials, etc. Such EER is based on the modular principle and usually comprises several parts: theoretical part, based on resource text, graphics (diagrams, charts, tables, and drawings), animation, audio and video, and an interactive unit; the practical part, which presents the solution of typical problems and exercises on the subject or training course.

However, along with the undoubted advantages EER also has disadvantages, e.g. many sites declared as "sites for children", however, are not safe, they can contain harmful and even dangerous content. So the selection of educational resources must meet the following requirements: 1) the site must meet the modern requirements of visual design (high quality graphics, accurate selection of fonts and colors, the relevance of the format, etc.); 2) the site must meet modern requirements for the structure and navigation functions of the Internet resource (accessible interface, easy navigation through the sections of the site); 3 ) the site must not contain information which content does not meet legal or moral standards; 4) the site must not contain advertisements (text or visual text) or contextual advertising.

Here it is important to emphasize that for the organization of educational work the teacher needs to make a list of secure sites recommended for information search.

\section{B. The Basic Principle of the Functional of the EER in Foreign Language Teaching}

The basic principle of the functioning of the EER in Foreign Language Teaching is a division of educational content into modules according to thematic elements and components of the educational process. By educational content, we understand structured by topics content of training and significant information content of the EER.

Foreign language is a unique subject, and using EER in its teaching may include:

- textual information (training, adapted or authentic texts, lectures, etc.); culture of the target language;

- media in which information may be submitted by the author of the resource or taken from other sources (e.g., films);

- graphics (paintings, photos, drawings, maps, diagrams, graphs, etc.).

Each thematic element of the subject should consist of three types of modules: an information module, the performance of practical tasks, and a module control of mastering the material.

The information module can be represented in the EER of a foreign language in different ways. It can be a lecture or a short presentation of theoretical material, the text on the topic or vocabulary, presentation, etc. The Module also includes list of available literature for the students with exact indication of pages. An important thing for the development of EER is a reference to external links to open resources, both domestic and foreign authors. An obligatory element of information support of the educational process at University is, for example, the electronic library systems that represents the database containing educational, methodical, scientific, reference and other publications.

In addition, there are plenty of sites designed for language learning or teaching and online dictionaries, electronic translators, trainings, encyclopedias, etc.

The module of performing practical tasks consists usually of files containing tasks for individual performance, exercises, laboratory works, essay topics, abstracts or term papers, which must be accompanied by methodological recommendations. Assignments should be provided with keys for self-control. The performance of each task should help the student to learn how to communicate in the studied language - to speak and ask questions, to listen and understand, to read and write, to overcome cultural barriers.

A module control of mastering the material can be divided into two parts: self-monitoring and monitoring by the teacher. The most common and quite effective form of control is testing. For self-control lexical and grammatical tests, tests in reading and listening, questionnaires, etc. can be used. Monitoring by the teacher is carried out through forums, chats, etc. And it is the main indicator of the presence of feedback between the author of EER and the student.

C. Criteria for Assessing the Quality of EER

The main criteria of the quality of EER are the following: - accordance with the training program; 
- the scientific validity of the submitted material (accordance with modern knowledge of the subject);

- providing all components of the educational process: information; practical training; certification (control of educational achievements).

- sufficient material and the methodological elaboration of the educational material presented;

- interactivity as a property that determines the nature and degree of user interaction with EER elements;

- multimedia as a property that determines the quantity and quality of presentation forms used in the EER;

- modifiability as a property that determines the possibility and complexity of making changes in the content and software of the EER.

\section{Implementation of general didactic and specific principles of Foreign Languages Teaching when using EER .}

The analysis confirmed that the technology of integrating the developed EER in the educational course is based on the interaction of both general didactic principles and specific principles of teaching.

The principle of visuality in the developed electronic materials is realized due to the use of multimedia, drawings, schemes, video files and is interpreted as the principle of polycode.

The principle of accessibility and adaptability and also the scientific principle are realized due to the possibilities of electronic educational resources which can ensure the systematizing and summarizing material, generate an additional illustrative material, provide graphic and video interpretations of the studied concepts on the basis of wide coverage of the material.

The principle of connection of theory with practice is achieved through the passing theoretical block of electronic resources to the unit of additional materials or the unit of materials for seminars through hyperlinks.

The principle of durability in mastering knowledge, abilities and skills is realized in structuring the material so that the student has the opportunity to apply consistently to theoretical material, practical block, reference information, and perform exercises after each studied topic.

The principle of modularity as one of the specific principles, involves the structuring of information in accordance with the curriculum through a specific sequencing of parts of the systematically organized teaching material.

The principle of interactivity and multimedia is realized through the expense of the possibility of choosing the options for the content of the educational material and the mode of work, that is, the Student - Content Interaction.

\section{RESULTS AND DISCUSSION}

Currently, the use of EER in the educational process in Elabuga Institute of KFU is realized in different ways, including the use of LMS MOODLE LMS (Learning Management System Module Object-Oriented Dynamic Learning Environment). It is a learning management system that allows to create distance learning courses (e-learning courses), which includes all the necessary training, support and control materials (or links to them) as well as methodological instructions (for both the teacher and the trainee) in accordance with curriculum.

The introduction of e-learning system based on LMS MOODLE is a multifaceted task and requires an integrated approach to its solution. The development of EER course is a complex and labor intensive process, which includes the following stages: the structure of the course; preparation of training materials; their placement in LMS MOODLE; the integrating of the course in the curriculum. That is why the teachers first have to study the technology of EER development in the special training courses under the program "Theory and practice of using LMS MOODLE in training".

We suggest the results of experiment that was held on the basis of Elabuga Institute of Kazan Federal University.

The group of the first year students of the Department of Foreign Languages were chosen randomly to be the sample of the experiment. The total number of the students was 50 . The students of this group were appointed randomly into two groups; the control group which had (25) students, and the other experimental group which had (25) students. All the students included in this study had the same learning experience and used the same text books. Students during the second term were selected to achieve the purpose of this study because the second term is an important stage during which students' language proficiency is an indicator of their language competence. In order to achieve the purpose of the study, a set of research instruments was developed: Reading Comprehension Test and Grammar Test. Both Tests consisted of 17 multiple choice questions. Students were given twenty minutes to answer the questions. Test items had variants, only one of which was correct.

To ensure the equivalence of the two groups before starting the study, a pre-test was applied. Table (1) shows the results:

TABLE 1. RESULTS OF PRE-TEST OF THE EQUIVALENCE OF THE TWO GROUPS

\begin{tabular}{|c|c|c|c|c|}
\hline \multirow{2}{*}{ PRETEST } & Group & students & $\begin{array}{c}\text { Mean } \\
\text { score } \\
\text { (reading } \\
\text { skills) }\end{array}$ & $\begin{array}{c}\text { Mean score } \\
\text { (grammar } \\
\text { skills) }\end{array}$ \\
\cline { 2 - 5 } & experimental & 25 & 4.1 & 3.8 \\
\hline
\end{tabular}

Table (1) shows that there were no statistically significant differences between the experimental and control group at the pre-test of reading comprehension and pre-test of grammar skills. This means that the control group and the experimental group were equivalent before starting the study.

During the second term students of the experimental group were taught a foreign language using EER, students of control group were taught a foreign language without using EER. Are there any significant differences in the students' reading comprehension and grammar skills due to the strategy of teaching with the help of EER? To answer this question mean 
score in the post tests was calculated. Table (2) presents the results in comparison.

TABLE 2. RESULTS OF USING EER IN TEACHING A FOREIGN LANGUAGE FOR EACH GROUP (CONTROL AND EXPERIMENT)

\begin{tabular}{|c|c|c|c|}
\hline Group & Students & Test & Mean score \\
\hline \multicolumn{4}{|c|}{ Test (reading skills) } \\
\hline control & 25 & PRETEST & 4.1 \\
\hline control & 25 & POSTTEST & 4.2 \\
\hline experimental & 25 & PRETEST & 4.0 \\
\hline experimental & 25 & POSTTEST & 4.5 \\
\hline \multicolumn{5}{|c|}{ Test (grammar skills) } \\
\hline control & 25 & PRETEST & 3.8 \\
\hline control & 25 & POSTTEST & 3.9 \\
\hline experimental & 25 & PRETEST & 3.9 \\
\hline experimental & 25 & POSTTEST & 4.6 \\
\hline
\end{tabular}

Table (2) shows the mean scores of the two groups (Control and Experimental). In the preReading Comprehension Test were (4.1) and (4.0) respectively while in the post test were (4.2) and (4.5) respectively; in the preGrammar Test were (3.8) and (3.9) respectively while in the post test were (3.9) and (4.6) respectively. This means that the students' reading comprehension and grammar skills scores in experimental group were improved in the post test because of the use of EER.

Thus, the study investigated the effectiveness of using EER in Foreign Languages Teaching at University. The results showed that there were statistically significant differences in students reading comprehension and grammar skills due to the strategy of teaching (teaching using EER and teaching without using EER) in favor of the EER - teaching strategy.

The results showed that using EER at the lessons of foreign languages might have contributed to the improvement of students' achievement in reading comprehension and in grammar. Students might have the opportunity to receive information from different resources, share their knowledge and skills in an appropriate manner and interact more effectively.

\section{CONCLUSIONS}

The development and implementation EER in Foreign Languages Teaching significantly expands the boundaries of learning, making it more diverse and effective. Thanks to electronic educational resources, the possibility of distance learning is realized, which is an important condition for the organization of the modern educational process.

The present study indicates that EER integrated into the educational process of students-linguists, successfully interacts with traditional means and forms of Foreign Languages Teaching and promotes not only the transmission of knowledge and the development of language competences but also the development of all components of the ICT, optimizing the educational process and increasing motivation of students to educational activity.

Lesson planning with the use of electronic educational resources requires from teachers a high degree of professional competence, namely, informational, analytical, predictive and projective skills in preparation for a lesson, as well as organizational and delivery skills during his/her pedagogical implementation. Additionally, creation of EER is a complex work for a teacher connected with mastering new technologies, development and putting the educational and methodical material in LMS MOODLE, introduction of a course in the educational process, management of students' self-guided work in the virtual educational environment. Therefore, the development department of the Kazan Federal Universityof educational resources provides distance 24-hour training teachers on the programme "Theory and Practice of Using LMS MOODLE in Teaching".

This study does not exhaust the fullness of the studied problem. Prospects for further research work can be seen in the following areas: consideration of the potential use of electronic educational resources for other subjects of the University curriculum; the organization of experimental work on the use of electronic educational resources in teaching at various levels (school, gymnasium, University); the reflection of the aspects of this study in the process of preparation of future teachers of foreign languages on the basis of Teachers Training Institutes.

\section{REFERENCES}

[1] Bilyalova, A. (2017). ICT in Teaching a Foreign Language in High School // Procedia - Social and Behavioral Sciences 237 ( 2017 ) 175 - 181.

[2] Boucher, A. (1998). Information technology-based teaching and learning in higher education: a view of the economic issues // Journal of Information Technology for Teacher Education. - 7 (1). - 87-111.

[3] Burns, M. (2011). Distance Education for Teacher Training: Modes, Models and Methods. Retrieved September 3, 2013, from http://www.idd.edc.org/resources/publications/modes-models-and-methods

[4] Dudeney, G. (2008). How to Teach English with Technology. Pearson Longman.

[5] Educational Benefits of Online Learning. (1998). CalPoly.edu. Retrieved March, 29, 2013, from http://www.blackboardsupport.calpoly.edu/content/faculty/handouts/Ben_Onl ine.pdf

[6]_Moore, M., \& Anderson, W. (2012). Handbook of Distance Education (2nd ed.). Psychology Press. Retrieved October 1, 2014, from

http://www.books.google.ru/books?id= IqeYfDpWGIC\&printsec=frontcover \&hl $=$ ru\&source $=$ gbs ge summary $\mathrm{r} \& \mathrm{cad}=0 \# \mathrm{v}=$ onepage $\& \mathrm{q} \& \mathrm{f}=$ false

[7] Sorin, R. (2005) Webfolio - Using Electronic Portfolios in Preservice Teacher Education. Australian Journal of Teacher Education. 30(1) Available in : http://www.ajte.education.ecu.edu.ua/issues/PDF/ThirtyOne/Sorin

[8] Stephens, D. (July 2007). Quality issues in distance learning. Retrieved September 6, 2013, from www.aacsb.edu/ /media/AACSB/.../wp-qualityissues-in-distance-edu.ashx

[9] Szendeffy, J. (2005). A Practical Guide to Using Computers in Language Teaching, East Lansing: University of Michigan Press/ESL.

[10] Wheeler, S. (2001). Information and communication technologies and the changing role of the teacher. Journal of Educational Media, 26 (1), 7-17.

[11] W. Horton, K. Horton (2005). "Electronic education: instruments and technologies." Moscow: Kudits Publishing House, - p. 640. 